\title{
Entedoninae wasps (Hymenoptera, Chalcidoidea, Eulophidae) associated with ants (Hymenoptera, Formicidae) in tropical America, with new species and notes on their biology
}

\author{
Christer Hansson ${ }^{1, \dagger}$, Jean-Paul Lachaud ${ }^{2,3, \ddagger}$, Gabriela Pérez-Lachaud ${ }^{2, \S}$
}

I Scientific Associate of Entomology Department, the Natural History Museum, London SW7 5BD, United Kingdom 2 El Colegio de la Frontera Sur, Entomologia Tropical, Av. Centenario Km 5.5, Chetumal 77014, Quintana Roo, Mexico 3 Centre de Recherches sur la Cognition Animale, CNRS-UMR 5169, Université de Toulouse UPS, 118 route de Narbonne, 31062 Toulouse Cedex 09, France

† urn:lsid:zoobank.org:author:EC91EABD-7115-4B05-BC80-9195C86FA55D

¥ urn:lsid:zoobank.org:author:B7356DAD-FB61-4F1F-B7FC-1563AFCED2A9

§ urn:lsid:zoobank.org:author:226D5EE2-02F7-4D72-9BDF-D9EAAOCEBCF4

Corresponding author: Christer Hansson (christerdennis@gmail.com)

Academic editor: Michael Sharkey | Received 2 June 2011 | Accepted 2 September 2011 | Published 6 October 2011

urn:lsid:zoobank.org:pub:469CD7C7-E4E0-4BE4-98B3-F8BBCCDF3580

Citation: Hansson C, Lachaud JP, Pérez-Lachaud G (2011) Entedoninae wasps (Hymenoptera, Chalcidoidea, Eulophidae) associated with ants (Hymenoptera, Formicidae) in tropical America, with new species and notes on their biology. ZooKeys 134: 65-82. doi: 10.3897/zookeys.134.1653

\begin{abstract}
Three new species of Eulophidae associated, or presumed to be associated with ants are described: two species of Horismenus Walker and one species of Microdonophagus Schauff. Information on the biology is also included. The two Horismenus species are from Chiapas, Mexico. Horismenus myrmecophagus sp. n. is known only from females and is a gregarious endoparasitoid in larvae of the weaver ant Camponotus sp. ca. textor. The parasitoids pupate inside the host larva, and an average of 6.7 individuals develops per host. This is the second time a species of genus Horismenus is found parasitizing the brood of a formicine ant of genus Camponotus. Horismenus microdonophagus sp. $\mathbf{n}$. is described from both males and females, and is a gregarious endoparasitoid attacking the larvae of Microdon sp. (Diptera: Syrphidae), a predator on ant brood found in nests of Camponotus sp. ca. textor. The new species of Microdonophagus, M. tertius, is from Costa Rica, and known only from the female. Nothing is known about its biology but since another species in same genus, $M$. woodleyi Schauff, is associated with ants through its host, Microdon larva (with same biology as $H$. microdonophagus), it is possible that also M. tertius has this association. A new distributional record for M. woodleyi is also reported, extending its distribution from Panama and Colombia to Brazil.
\end{abstract}

Copyright Christer Hansson et al. This is an open access article distributed under the terms of the Creative Commons Attribution License, which permits unrestricted use, distribution, and reproduction in any medium, provided the original author and source are credited. 


\section{Keywords}

Horismenus, Microdonophagus, Camponotus, Microdon, ant parasitism, myrmecophile, taxonomy

\section{Introduction}

Natural enemies of ants include dipteran, strepsipteran and hymenopteran parasitoids (for a review see Wilson (1971), Kistner (1982), Hölldobler and Wilson (1990)). Species of several families of parasitic wasps have been reported parasitizing brood or adult ants, the Eucharitidae being the only monophyletic group, at the family level, where all members are parasitoids of ants (Heraty 2002). In contrast to eucharitids, parasitization of ants by eulophids is a rare event.

Four associations involving a eulophid wasp and an ant host have been reported to date, and all are genera belonging to the subfamily Entedoninae: an unidentified gregarious parasitoid, apparently closely related to the genus Paracrias Ashmead (identified by Gahan), was recorded parasitizing larvae of the myrmicine Crematogaster acuta (Fabr.) in Guyana (Wheeler and Wheeler 1924), the prepupae of another, unidentified species of Crematogaster were parasitized by Myrmokata diparoides Bouček (Bouček 1972) in Cameroon, Pediobius marjoriae Kerrich was reared from cocoons of Lepisiota sp. (referred to as Acantholepis sp.) (Formicidae: Formicinae) in Uganda (Kerrich 1973), and Horismenus floridensis (Schauff \& Bouček) (referred to as Alachua floridensis) was found parasitizing the pupae of Camponotus atriceps (F. Smith) (referred to as C. abdominalis Fab.) and of C. floridanus (Buckley) (Formicidae: Formicinae) in Florida (Schauff and Bouček 1987). Three other species of Eulophidae (the first two are Entedoninae, the third a Tetrastichinae) have been reported associated with ant nests but direct parasitism on the ant brood was not clearly established in any of these cases: Myrmobomyia malayana Gumovsky \& Bouček with nests of an ant species of the genus Dolichoderus in Malaysia (Gumovsky and Bouček 2005), an unidentified species of Horismenus from the bivouac and refuse deposits of the army ant Eciton burchellii (Westwood) (Rettenmeyer et al. 2011), and an unidentified species of Tetrastichus from a nest of Myrmecocystus mexicanus Wesmael in USA (Wheeler and Wheeler 1986). Finally, two species of Entedoninae are indirectly associated with ants as they parasitize insects living in ant nests: Kerrich (1973) reported Pediobius acraconae Kerrich from the last instar larva of Acracona remipedalis Karsh (Lepidoptera: Pyralidae) living in a nest of Crematogaster depressa (Latreille) or C. africana Mayr (Formicidae: Myrmicinae) in Nigeria, and Microdonophagus woodleyi Schauff parasitizes larvae of Microdon sp. (Diptera: Syrphidae), living in nests of Technomyrmex fulvus (Wheeler) (referred to as Tapinoma fulvum) (Formicidae: Dolichoderinae) (Schauff 1986).

Here we describe two species of Horismenus, one parasitizing the brood of the weaver ant Camponotus sp. ca. textor, and the other parasitizing a syrphid myrmecophile associated with this ant species. A new species of Microdonophagus Schauff 
presumed to be associated with ants is also described. A new distributional record for M. woodleyi is provided.

\section{Methods}

Specimens for this study were either reared (Horismenus species) or collected manually (Microdonophagus), killed in alcohol, and subsequently critical point dried and mounted on cards for further studies. Observations of the specimens were made through a stereomicroscope, Nikon ${ }^{\circledR}$ SMZ 1500 with a halogen ring light as light source. The colour photos were taken with a DS-Fil camera mounted on the stereomicroscope and the light source for the photos was a dome light manufactured from a description on http://www.cdfa.ca.gov/. Each picture was made from several photos taken at different levels of focus, and merged using Helicon Focus ${ }^{\odot}$. Micrographs are from uncoated specimens analyzed in low vacuum, with a JEOL ${ }^{\odot}$ JSM 5600 LV scanning microscope.

\section{Morphological abbreviations and acronyms}

Abbreviations for morphological terms: $\mathrm{DE}=$ shortest distance between eyes in frontal view; $\mathrm{DO}=$ diameter of median ocellus; $\mathrm{HE}=$ height of eye; $\mathrm{HW}=$ height of fore wing; LC = length of median carina on propodeum; LG = length of gaster; LM = length of marginal vein; LS = length of hind tibial spur; LT = length of hind tarsus; $\mathrm{LW}=$ length of fore wing, measured from base of marginal vein to apex of wing; $\mathrm{MM}=$ length of mesosoma; $\mathrm{MS}=$ malar space OOL = distance between one posterior ocellus and eye; $\mathrm{PM}$ = length of postmarginal vein; $\mathrm{POL}=$ distance between posterior ocelli; $\mathrm{POO}=$ distance between posterior ocelli and occipital margin; ST = length of stigmal vein; WC = greatest width of median carina on propodeum; WH = width of head; WM = width of mouth; WT = width of thorax. For illustrations of the morphological terms see http://www.neotropicaleulophidae.com/.

Collection acronyms used are: $\mathrm{BMNH}=$ The Natural History Museum, London, England; $\mathrm{CH}$ = collection of Christer Hansson; ECO-CH-AR = Arthropod Collection El Colegio de la Frontera Sur-Chetumal, Mexico; USNM = the United States National Museum of Natural History, Washington, D.C., USA.

\section{Taxonomy}

\section{Genus Horismenus Walker}

There are 400 species described of the almost exclusively New World genus Horismenus Walker, 1843, mostly from the Neotropical region (Hansson 2009a), but only 13 have 
been reported from Mexico. Host records are available for 99 Horismenus species (Pérez and Bonet 1984, Bonet 2008, Hansson 2009a). The genus shows a wide host spectrum including lepidopteran and coleopteran leaf-miners, seed-eating bruchids and curculionids, coccids, mantispids, spider eggs, and both dipteran and hymenopteran parasitoids. Members of this genus also display a variety of life styles. Records include both primary and secondary parasitoids, solitary or gregarious species, specialist or generalist parasitoids, and as far as is known all are endoparasitoids and presumably koinobionts. The species may attack eggs, larvae, or pupae of their hosts.

\section{Horismenus myrmecophagus sp. $\mathrm{n}$.}

urn:lsid:zoobank.org:act:CE88218A-4A94-4FD3-B87C-09C5442AA1AA http://species-id.net/wiki/Horismenus_myrmecophagus

Figures 1, 2-6, 17, 21, 23-24

Material. HOLOTYPE female (BMNH), glued to a card, labelled "MEXICO: Chiapas, Tuxtla Chico, Rosario Izapa, $14^{\circ} 58^{\prime} 25^{\prime}$ N 92 09'19”W, 430 m, 25.ii.2010, G. Pérez-Lachaud \& J.-P. Lachaud, reared from Camponotus sp. ca. textor pupa, nest no. 2, on mandarine (Citrus reticulata)". PARATYPES. $1+$ with same label data as holotype (BMNH); 29 우 with same label and host data as holotype but collected from nest \#3 28.ii.2010 (22ㅇ in BMNH, 2 q in CH, 5 in ECO-CH-AR). Several paratypes have opaque and somewhat distorted wings due to premature killing in alcohol, i.e. before the wing membranes had hardened.

Diagnosis. Frons with interscrobal area protruding and carinate (Fig. 2); scutellum entirely reticulate, without median groove and lateral mesh-rows (Fig. 4); fore wing speculum small and closed below (Fig. 21); all coxae white; propodeum with submedian grooves strongly reticulate and with anterolateral foveae weakly indicated anteriorly (Fig. 5); propodeal callus with five setae.

The species is very similar to $H$. alienus Hansson, but differs mainly in the shape of the petiole which in $H$. alienus has a strongly raised transverse carina dorsally, but $H$. myrmecophagus has two strong and rounded projections dorsolaterally (Fig. 5); it differs also in sculpture of median propodeum: smooth in $H$. alienus, but strongly reticulate in H. myrmecophagus (Fig. 5).

Description. Female. Length of body 1.1-1.4 mm. Scape white; pedicel and flagellum pale brown. Frons golden-green with purple tinges (Fig. 23). Vertex metallic bluish-green. Mesoscutum metallic bluish-green (Fig. 24). Scutellum dark goldenpurple with green tinges (Fig. 24). Propodeum dark golden-purple (Fig. 24). Legs white. Wings hyaline. Petiole dark golden-purple. Gaster dark brown with metallic purple tinges.

Antenna as in Fig. 17. Frons (Fig. 2) with part just above frontal suture with raised and weak reticulation, remaining parts with raised and strong reticulation; frontal suture V-shaped, incomplete and not reaching eyes; antennal scrobes joining frontal 


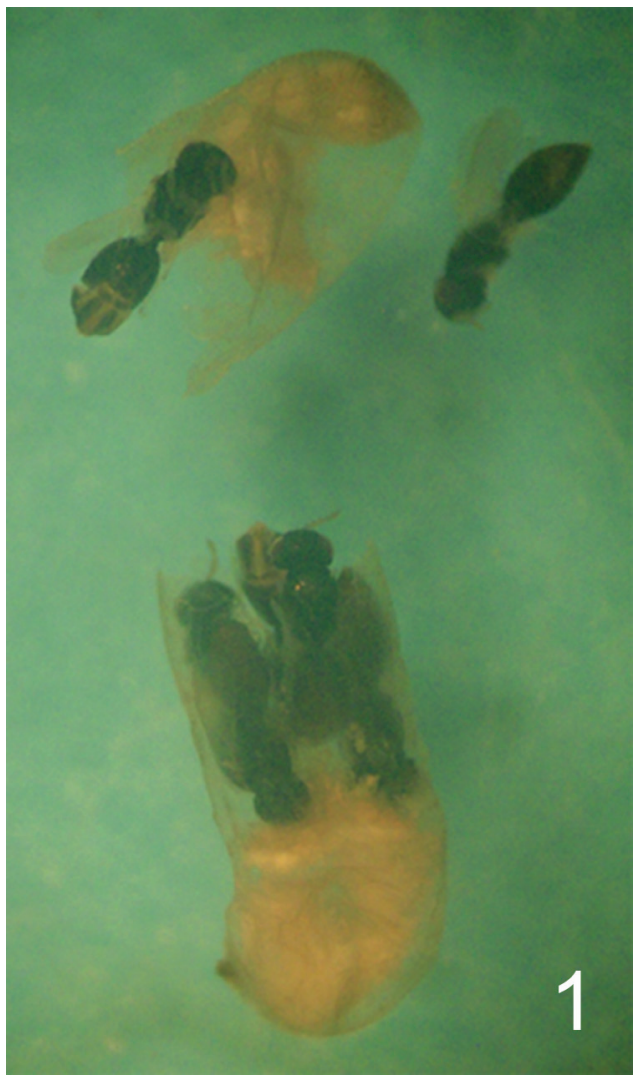

Figure I. Camponotus sp. ca. textor larva parasitized by Horismenus myrmecophagus. H. myrmecophagus develops as a gregarious endoparasitoid. The ant larva has been cut open (its head is at the bottom of the picture). Several pupae of the eulophid parasitoid may be observed, some of them still inside the ant larva.

suture separately. Vertex (Fig. 3) with raised and strong reticulation; without a median groove. Occipital margin rounded.

Mesoscutum with raised and strong reticulation (Fig. 4); notauli indistinct. Scutellum with raised and strong reticulation (Fig. 4), without median groove and lateral mesh-rows. Dorsellum slightly concave and with raised and strong reticulation. Propodeum with raised and strong reticulation (Fig. 5); propodeal callus with five setae. Coxae with raised and weak reticulation. Fore wing speculum small and closed below (Fig. 21); with 12 admarginal setae.

Gaster (Fig. 6) with first tergite with very weak reticulation posteriorly and laterally, otherwise smooth.

Ratios. DE/DO 6.9; WH/DE 1.9; HE/MS/WM 2.4/1.0/2.0; POL/OOL/POO 2.5/1.0/1.1; WH/WT 1.2; LW/LM/HW 1.8/1.0/1.0; PM/ST 1.4; LC/WC 1.4; WG/ WC 2.0; LS/LT 0.22; MM/LG 1.0.

Male. Unknown. 


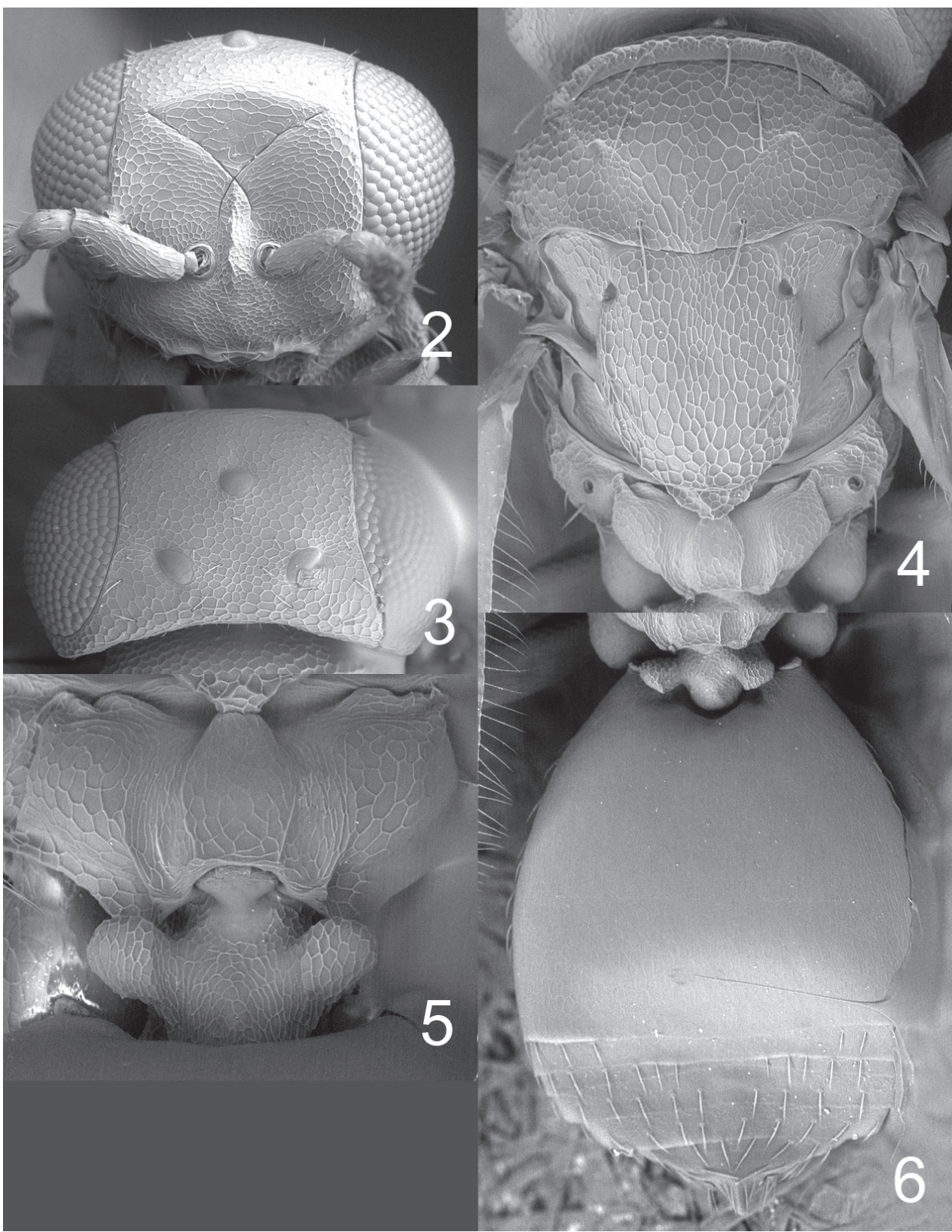

Figures 2-6. Horismenus myrmecophagus female: $\mathbf{2}$ head in frontal view $\mathbf{3}$ vertex $\mathbf{4}$ thoracic dorsum 5 propodeum $\mathbf{6}$ gaster in dorsal view.

Etymology. Named after the feeding habits of the larva (from the Greek myrmecophagus $=$ ant eater $)$.

Distribution. Mexico (Chiapas). 
Biology. Horismenus myrmecophagus is a gregarious endoparasitoid of the larvae of Camponotus sp. ca. textor, a neotropical weaver ant. Parasitized host larvae spin a cocoon before their development is arrested, but no pupation occurs. Parasitized ant larvae are not modified in external form or color by the developing parasitoids, but changes in appearance were observed in the host at the end of the wasp larval development. In material preserved in alcohol, late instar larvae, pupae and teneral adults of the wasps can be readily observed inside ant larvae, within the host cocoon, but earlier developmental stages of the parasitoids could not be detected. The wasp larvae pupate inside the host larva. Horismenus individuals occupy almost the entire body of the host. Wasp pupae were found aligned on either part of the middle of the body of the host, their heads converging to the center, while the cephalic and caudal portions of the host larva were occupied by the host remains and the parasitoids meconia (Fig. 1). An average of 6.7 individuals developed per host (range: $4-12$, mode: $7, n=27$ parasitized cocoons examined). Adults emerge from the host cocoon through a unique, common hole pierced in the host larval cuticle and through the cocoon wall, but it is unknown whether adult wasps leave the nests to mate. Only females have been observed to date (all broods examined, where the sex of the parasitoid could be ascertained, were constituted by females ( $\mathrm{n}=10$ parasitized hosts)). The facts that only single sex broods parasitize any one host, and that only females are known, suggest that $H$. myrmecophagus is a thelythokous species. Large ant larvae (presumably queens) have never been observed to be parasitized.

Camponotus sp. ca. textor (until now referred to in the literature as C. senex textor Forel) is a common, dominant ant in shade coffee plantations in the Soconusco Region of Chiapas, Mexico (Philpott 2005). This species builds aerial nests on various native and introduced trees (Inga sp., Citrus reticulata, C. sinensis) with the silk of their larvae. Nests measure up to $40 \mathrm{~cm}$ in diameter, and colonies may comprise up to 30.000 individuals (Pérez-Lachaud and Lachaud, unpublished data).

The host range of $H$. myrmecophagus is unknown. It is possible that this species may attack other ant species occupying similar niches, given that certain species of Horismenus are known to be polyphagous (e.g. H. aeneicollis, H. apantelivorus, H. opsiphanis or H. sardus, see Hansson 2009a), and that other ants are known to be parasitized by eulophids in the type locality (e.g. Pachycondyla crenata (Roger), A. de la Mora personal comment), and in French Guiana (e.g. Camponotus (Dendromyrmex) sp., G. Pérez-Lachaud and J.-P. Lachaud, unpublished data), though their identity has not been confirmed yet.

Remarks. The similar species $H$. alienus is known only from the female and its host/biology is unknown, but due to its morphological similarity to $H$. myrmecophagus it is possible that $H$. alienus is also a parasitoid of ants.

\section{Horismenus microdonophagus sp. $\mathrm{n}$.}

urn:lsid:zoobank.org:act:1848E913-005D-48C1-8431-870D4FACB80F http://species-id.net/wiki/Horismenus_microdonophagus

Figures 7-11, 18-19, 22, 25-27 


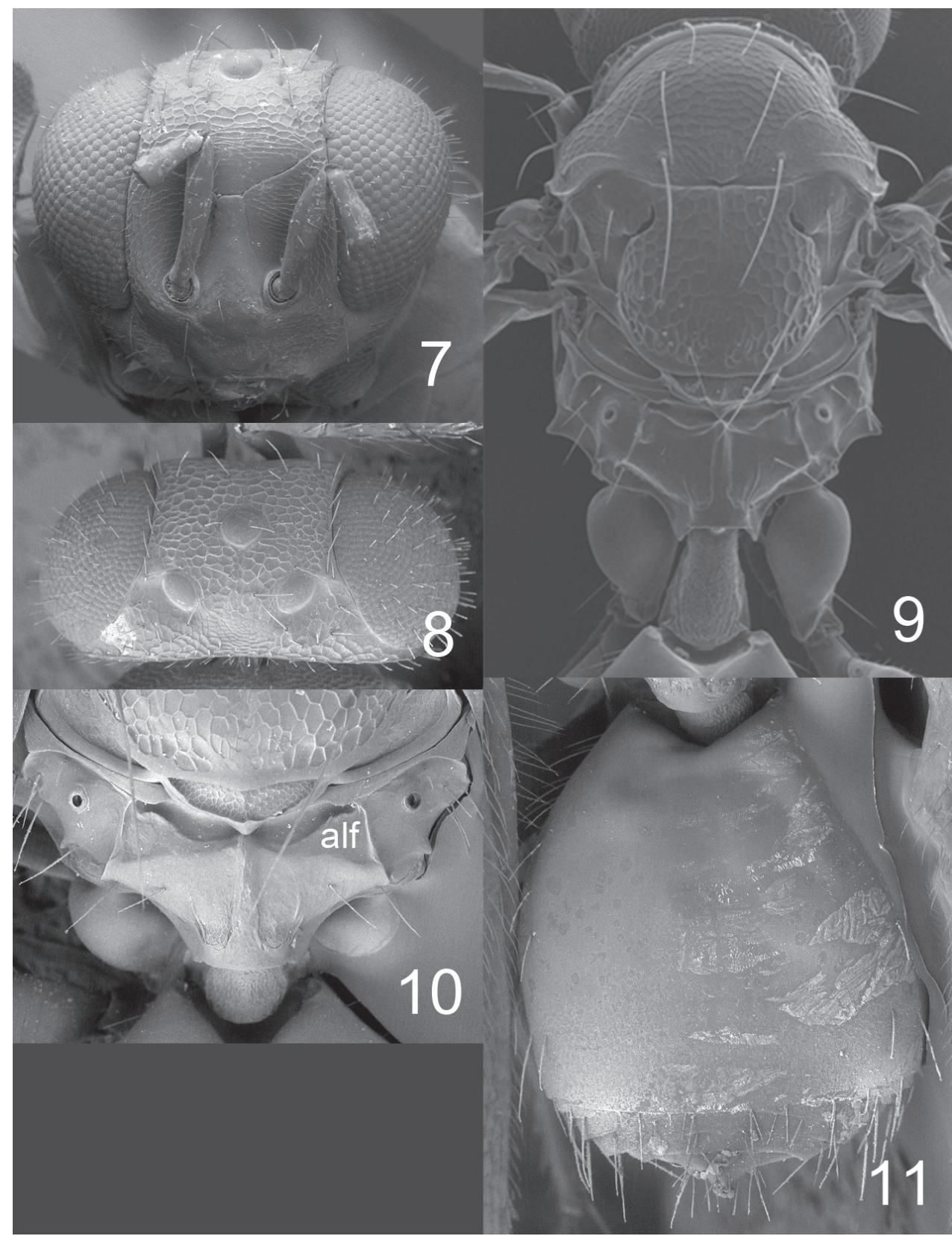

Figures 7-I I. Horismenus microdonophagus female: $\mathbf{7}$ head in frontal view 8 vertex 9 thoracic dorsum and petiole $\mathbf{I} \mathbf{0}$ propodeum $\mathbf{I} \mathbf{I}$ gaster in dorsal view. Abbreviation alf $=$ anterolateral fovea.

Material. HOLOTYPE female (BMNH) glued to a card, labelled "MEXICO: Chiapas, Tuxtla, Chico, Rosario Izapa, $14^{\circ} 58^{\prime} 25^{\prime} \mathrm{N} 92^{\circ} 09^{\prime} 19^{\prime}$ W, 430 m, 28.ii.2010, G. Pérez-Lachaud \& J.-P. Lachaud, reared from larva of Microdon sp., predator inside 
Camponotus sp. ca. textor, nest no. 3". PARATYPES. 10 우 20 with same label data as

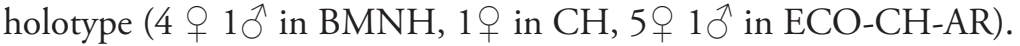

Diagnosis. Fore wing speculum covered with setae (Fig. 22); scutellum transverse, $0.75 \mathrm{X}$ as long as wide, entirely reticulate with raised and strong reticulation and with a narrow median groove in anterior half (Fig. 9); propodeum with a median carina but without submedian grooves (Fig. 10). This species is easy to recognize through these diagnostic features.

Description. Female. Length $2.0 \mathrm{~mm}$. Scape yellowish-brown, pedicel pale brown, flagellum dark brown. Frons dark golden-green (Fig. 25). Vertex golden-red. Mesoscutum golden-red with posterior 2/3 of midlobe metallic bluish-green (Fig. 26), to predominantly metallic bluish-green or golden-green. Scutellum golden with a median spot metallic bluish-green (Fig. 26), to predominantly metallic bluish-green. Propodeum metallic purple (Fig. 26). Coxae black to dark brown with golden-green tinges; femora, tibiae and tarsi yellowish-brown. Wings hyaline. Petiole black, shiny. Gaster metallic dark purple.

Antenna as in Fig. 18. Frons (Fig. 7) with interscrobal and clypeal areas and part just above frontal suture smooth, remaining parts with raised and strong reticulation with small meshes; frontal suture $\mathrm{V}$-shaped, incomplete not reaching eyes; antennal scrobes join with frontal suture separately. Vertex (Fig. 8) with raised and strong reticulation, areas just behind posterior ocelli smooth; posterior part without median groove. Occipital margin rounded (Fig. 8).

Mesoscutum and scutellum with raised and strong reticulation (Fig. 9); notauli as indistinct impressions, forming posterior part of midlobe to an indistinct triangle. Dorsellum concave with raised and strong reticulation. Propodeum smooth (Fig. 10) or with raised and weak reticulation; median carina narrow and weak; propodeal callus with 5-7 setae and with 2-3 additional setae on median part of propodeum. Coxae smooth. Fore wing speculum absent or very small, obliterated by setae (Fig. 22); with 15 admarginal setae.

Gaster (Fig. 11) with first tergite smooth and shiny with a very weak reticulate band close to posterior margin.

Ratios. DE/DO 4.2; WH/DE 2.4; HE/MS/WM 2.7/1.0/1.4; POL/OOL/POO 3.1/1.0/1.6; WH/WT 0.9; LW/LM/HW 1.9/1.2/1.0; PM/ST 1.7; LC/WC 4.0; WG/ WC 1.5; LS/LT 0.32; LP/WP 1.5; MM/LG 1.3-1.4.

Male. Length $1.6 \mathrm{~mm}$. The male is similar to the female except: scape inflated (Fig. 19) and dark brown, slightly longer petiole and shorter gaster.

Ratios. HE/MS/WM 2.4/1.0/1.2; LP/WP 1.6; MM/LG 1.6.

Etymology. Named after the feeding habits of larvae (from the Greek microdonophagus = eater of Microdon).

Distribution. Mexico (Chiapas).

Biology. Horismenus microdonophagus is a gregarious endoparasitoid of Microdon larvae (Diptera: Syrphidae), a predator on the brood of Camponotus sp. ca. textor. One Microdon sp. larva that was about to pupate was found inside a Camponotus nest. From this single host 79 females and 6 males of $H$. microdonophagus emerged. 
Remarks. One of the two males has the flagellum of both antennae missing, as have also some of the female paratypes, and the other male has the entire right flagellum and apical two flagellomeres of the left antenna missing. Only specimens in fair condition were included in the description, i.e. are type material. The remaining specimens were too fragmented to be included.

\section{Genus Microdonophagus Schauff}

This is an exclusively Neotropical genus recorded from Brazil, Colombia, Costa Rica and Panama (Schauff 1986, Hansson 2002, 2009b). It now includes three species but only in one species, M. woodleyi, is the biology known. This species is a gregarious endoparasitoid in larvae of Microdon sp. (Diptera: Syrphidae) living in nests of Technomyrmex fulvum (Formicidae: Dolichoderinae) (Schauff 1986). The same species also shows distinct sexual dimorphism, female being "normal" but male having several derived characters such as small eyes, reduced wings, and strongly inflated femora (Schauff 1986). Males are not known for the other two species.

\section{Microdonophagus tertius Hansson sp. $\mathbf{n}$.}

urn:lsid:zoobank.org:act:5DB16050-0C5D-41AE-A2EA-6D16981D2E2C http://species-id.net/wiki/Microdonophagus_tertius

Figures 12-16, 20, 28

Material. HOLOTYPE female (BMNH) glued to a card, labelled "COSTA RICA, Puntarenas, Parque Nacional Corcovado, Mosokha, Quebrada Hedionda, 15.iii-15. iv.2003, Khanaki."

Diagnosis. This species is similar to M. levis Hansson (Hansson 2009b) in its smooth and shiny thoracic dorsum but differs from the latter in several characters: scutellum without median groove (Fig. 14); propodeum with a narrow median carina and with distinct anterolateral foveae (Fig. 15); lower mesepimeron enlarged (Fig. 28) but not as enlarged as in M. levis (Fig. 29).

Description. Female. Length $2.0 \mathrm{~mm}$. Scape yellowish-brown, pedicel and flagellum pale brown. Head and body including gaster dark brown and shiny. Coxae pale brown; femora, tibiae and tarsi yellowish-brown. Wings hyaline.

Flagellum without anelli, with three funicular segments and a two-segmented clava (Fig. 20). Frons smooth and shiny (Fig. 12), without antennal scrobes and frontal suture, with a narrow and sharp process (an interantennal crest) between toruli. Vertex smooth and shiny (Fig. 13). Occipital margin sharp (Fig. 13). Eyes with scattered long hairs (longer than in M. levis). 


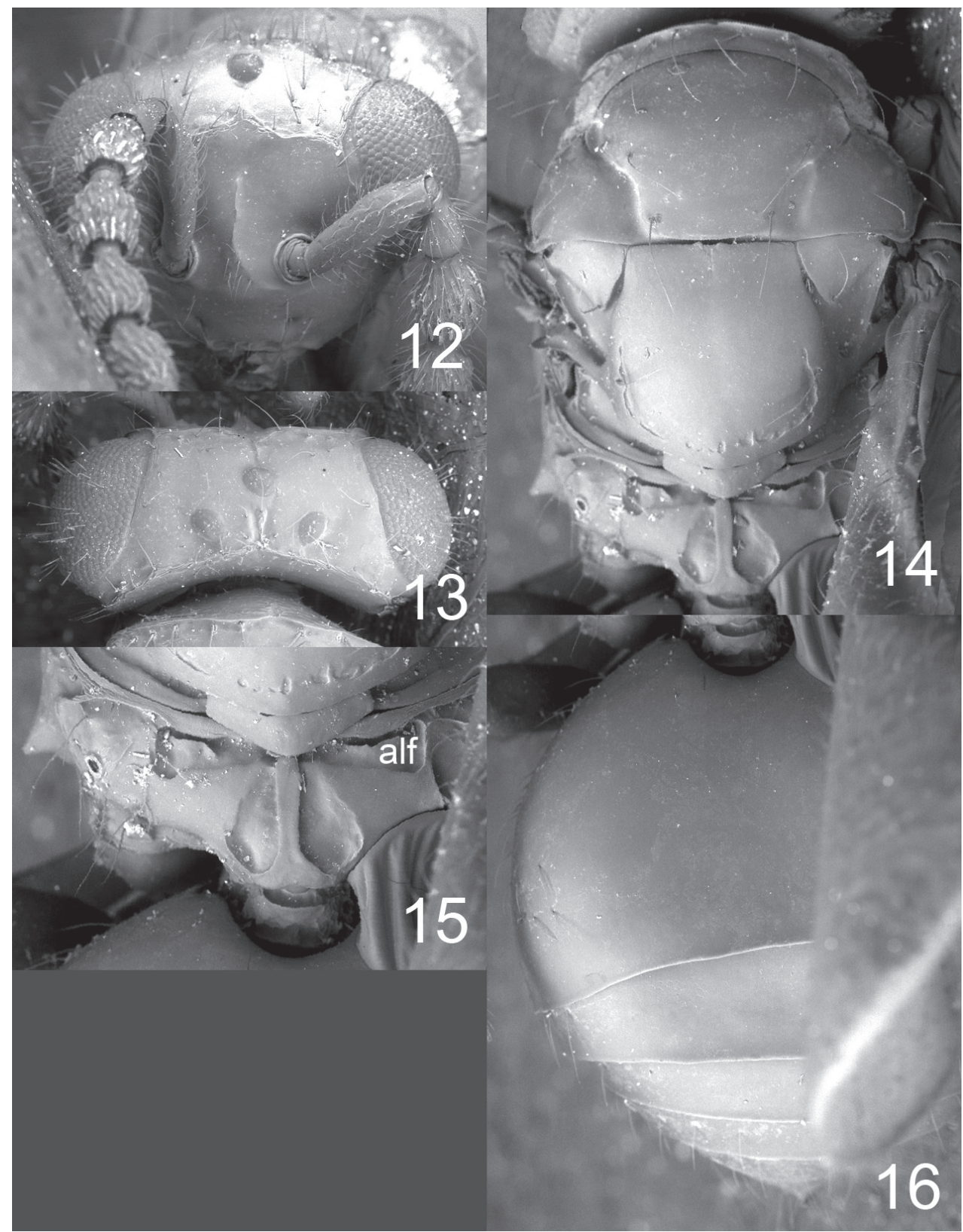

Figures I 2-16. Microdonophagus tertius female: $\mathbf{I} \mathbf{~ h e a d ~ i n ~ f r o n t a l ~ v i e w ~} \mathbf{I} \mathbf{3}$ vertex $\mathbf{1} \mathbf{4}$ thoracic dorsum $\mathbf{I 5}$ propodeum $\mathbf{1 6}$ gaster in dorsal view. Abbreviation alf = anterolateral fovea . 


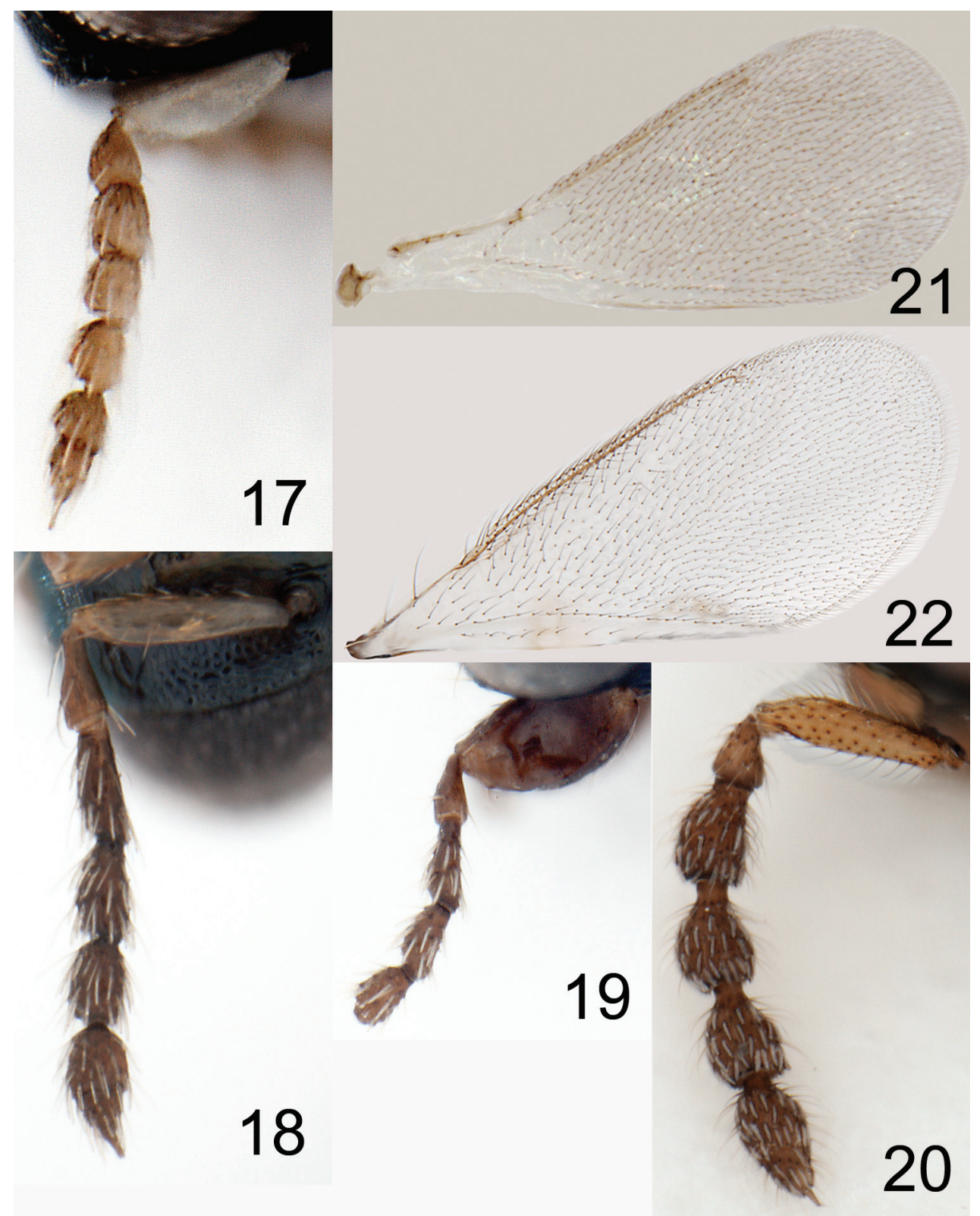

Figures 17-22. 17-20 antenna in lateral view: 17 Horismenus myrmecophagus female $\mathbf{1 8} \mathrm{H}$. microdonophagus female $19 \mathrm{H}$. microdonophagus male (apical 2 flagellomeres missing) 20 Microdonophagus tertius female. $\mathbf{2 1 - 2 2}$ right fore wing female: $\mathbf{2 1}$ H. myrmecophagus $\mathbf{2 2}$ H. microdonophagus. 


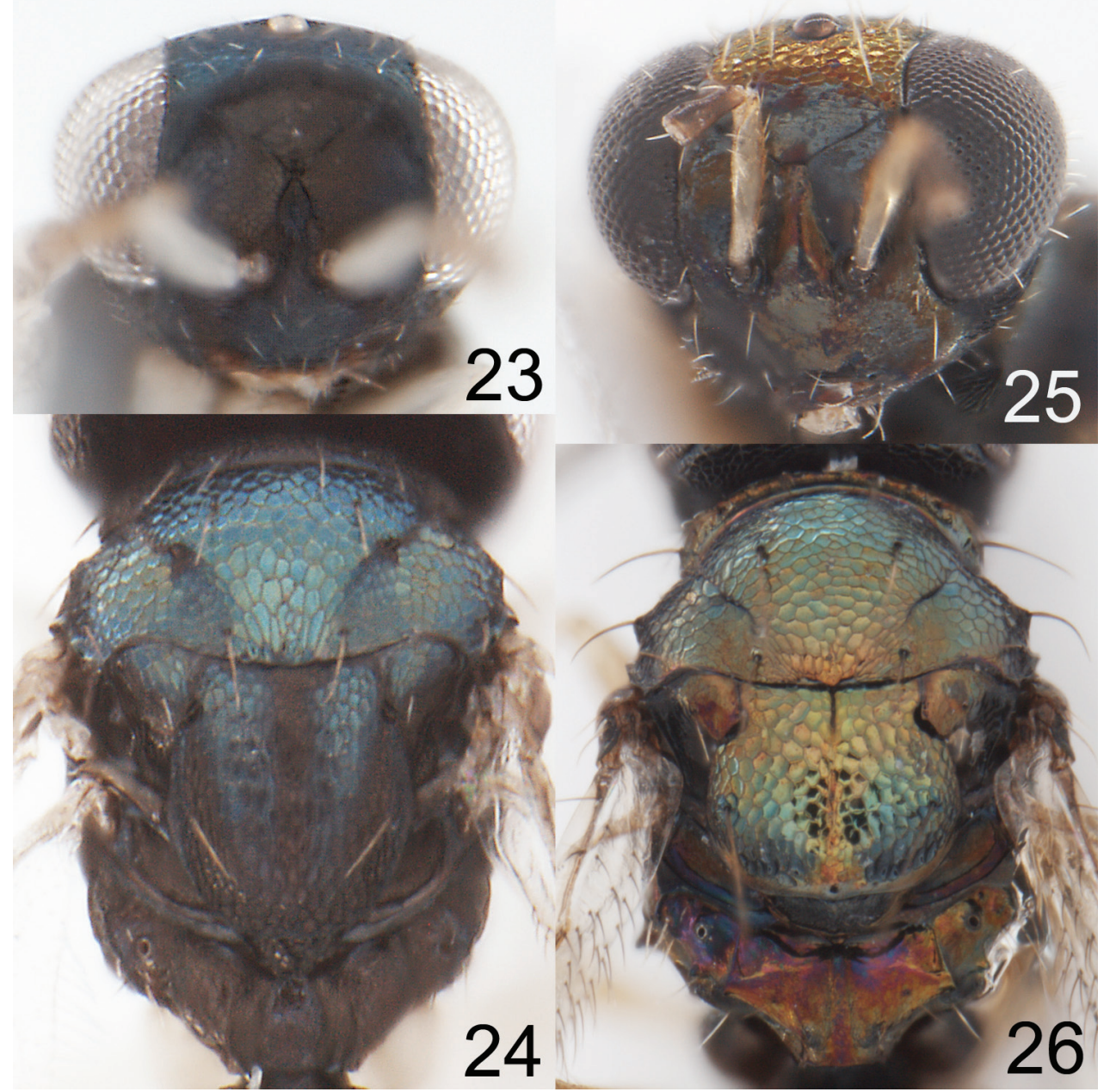

Figures 23-26. 23-24 Horismenus myrmecophagus female: $\mathbf{2 3}$ head in frontal view $\mathbf{2 4}$ thoracic dorsum. 25-26 Horismenus microdonophagus female: $\mathbf{2 5}$ head in frontal view $\mathbf{2 6}$ thoracic dorsum.

Mesoscutum smooth and shiny (Fig. 14); midlobe with two pairs of setae; notauli as distinct grooves throughout. Scutellum smooth and shiny (Fig. 14); with one pair of setae; with sublateral grooves in posterior half. Propodeum with a narrow median carina (Fig. 15); with wide sublateral grooves; with distinct anterolateral foveae; propodeal callus with about eight setae; propodeal surface smooth. Fore wing with four setae (right fore wing) and six setae (left fore wing) respectively on dorsal surface of submarginal vein; costal cell bare; speculum small and closed below; postmarginal vein not visible.

Petiole hidden behind inflated gaster but appears to be about as long as wide, dorsal surface with strong sculpture. Gaster circular; gastral tergites smooth (Fig. 16).

Ratios. HE/MS/WM 1.7/1.0/1.3; POL/OOL/POO 6.0/4.4/1.0; WH/WT 1.0; LW/LM/HW 1.7/1.0/1.0; LP/WP ca 1; MM/LG 1.0. 
Male. Unknown.

Etymology. From the Latin tertius = third. Named for this being the third species described in the genus.

Distribution. Costa Rica.

Biology. Unknown, but possibly associated with ants, as is the type species of $\mathrm{Mi}$ crodonophagus, M. woodleyi.

\section{Microdonophagus woodleyi Schauff}

http://species-id.net/wiki/Microdonophagus_woodleyi

Figure 30

Microdonophagus woodleyi Schauff, 1986: 170-172. Holotype female in USNM.

Distribution. Brazil (new record, 1 f from Santa Catarina, Nova Teutonia, 7.iv.1938, F. Plaumann, in BMNH), Colombia (Hansson 2002), Panama (Schauff 1986).

\section{Identification}

Horismenus and Microdonophagus can be identified using the matrix key to Entedoninae genera on the website http://www.neotropicaleulophidae.com/. These two genera share certain characters that indicate that they are sister-groups: multiporous plate sensilla on flagellomeres with upper surface concave; propodeum with median carina, submedian grooves and anterolateral foveae. However, they also possess characters that show that each genus is a distinct monophyletic group:

Horismenus Microdonophagus

Antennal spicule with apical seta... Antennal spicule with apical peg (apomorphy)

Antennal scrobes as grooves. Antennal scrobes not visible (apomorphy)

Frontal suture as groove Frontal suture not visible (apomorphy)

Axillar fovea present (apomorphy)

Lower mesepimeron normal. Axillar fovea missing Lower mesepimeron enlarged (apomorphy)

Species identification. (using modifications of the key in Hansson (2009a) below, but interactive keys on the website http://www.neotropicaleulophidae.com/, can also be used).

Horismenus myrmecophagus females run to subkey B and from there to couplet 5, first alternative, where $H$. myrmecophagus is differentiated from $H$. alienus as indicated above under diagnosis for $H$. myrmecophagus.

Horismenus microdonophagus females run to subkey D and from there to couplet 8 where the second alternative is chosen and this leads to 9a instead of 9, and then: 


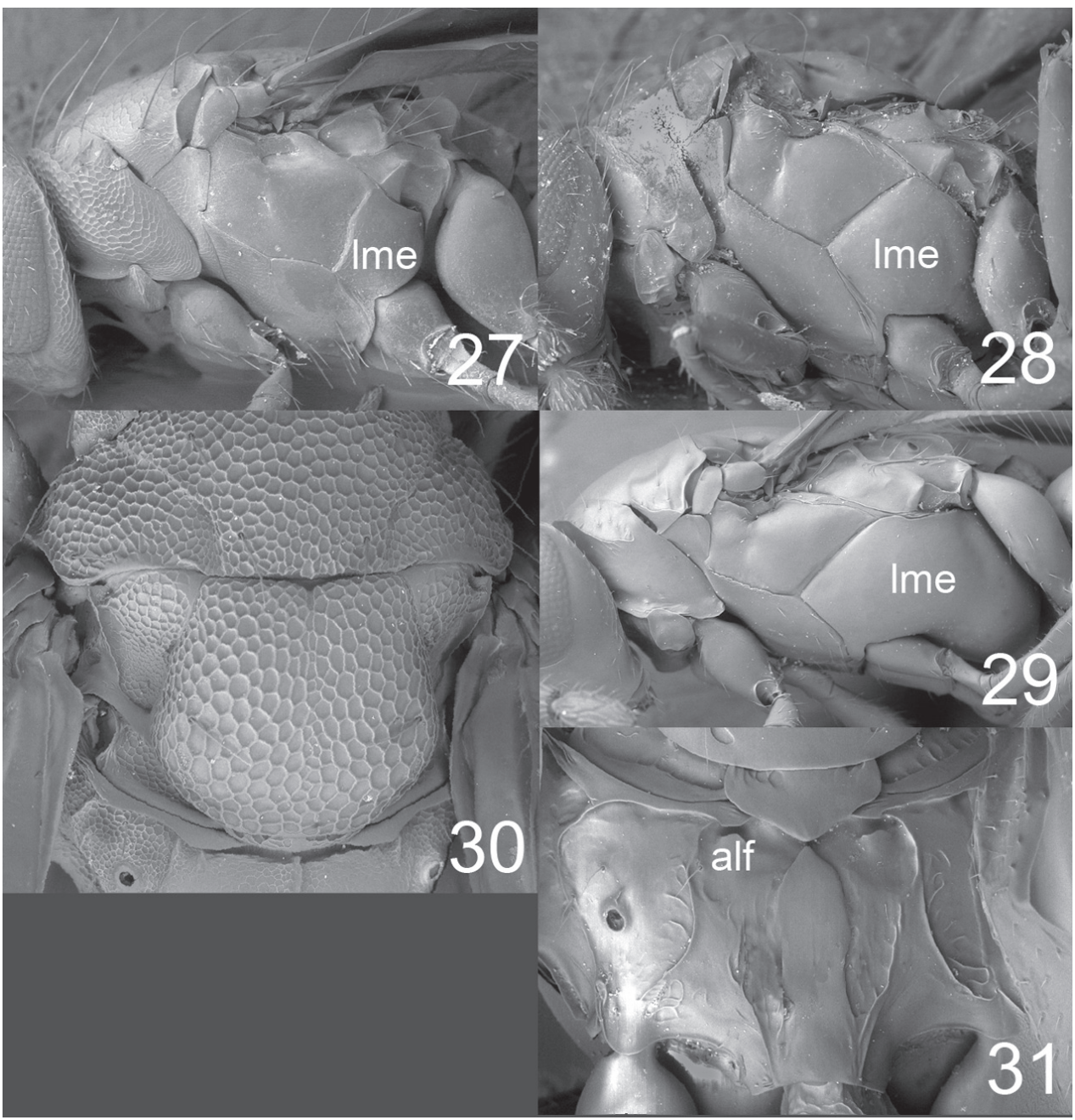

Figures 27-31. 27-29 mesosoma in lateral view females: 27 Horismenus microdonophagus 28 Microdonophagus tertius 29 M. levis Hansson 30 M. woodleyi Schauff, part of thoracic dorsum with scutellum. $3 \mathbf{I}$ M. levis, propodeum. Abbreviations alf = anterolateral fovea; $l m e=$ lower mesepimeron.

9a Fore wing speculum small (Fig. 22) and propodeum with a complete median carina (Fig. 10) ............................................ H. microdonophagus sp. $\mathbf{n}$.

- $\quad$ Fore wing speculum large, or median carina on propodeum mainly oblit-

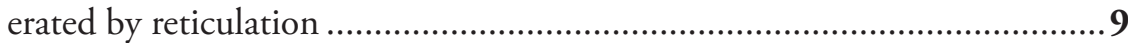

Horismenus microdonophagus males are difficult to include in the key because the antennal clava is missing. However, the combination of strongly inflated scape, transverse scutellum that is completely reticulate, small fore wing speculum, and propodeum without submedian grooves make males of this species easy to recognize (true also for females). 


\section{Key to all species of Microdonophagus}

1 Scutellum with raised and strong reticulation (Fig. 30)

- $\quad$ Scutellum predominantly smooth and shiny (Fig. 14).................................2

2 Lower mesepimeron (lme) strongly enlarged (Fig. 29); propodeum with indistinct anterolateral foveae (alf) (Fig. 31)........................... M. levis Hansson

- Lower mesepimeron (lme) smaller (Fig. 28); propodeum with distinct anterolateral foveae (alf) (Fig. 15) ................................................. tertius sp. n.

\section{Discussion}

Parasitization of ants is uncommon among Eulophidae and a survey of published literature showed that only four (possibly just three) eulophid genera, all Entedoninae, are recorded as parasitoids of ants. Apart from Horismenus (H. floridensis (Schauff and Bouček 1987), and H. myrmecophagus sp. n. (this article)), only an unidentified genus, possibly close to Paracrias (Wheeler and Wheeler 1924), the monotypic genus Myrmokata (Bouček 1972), and Pediobius (Kerrich 1973) have been undoubtedly associated as parasitoids of ants. The record in Wheeler and Wheeler (1924) is "apparently closely related to the genus Paracrias Ashmead, but I cannot identify it positively, even generically", attempt for identification and remark by A.B. Gahan. Paracrias spp. apparently exclusively target the order Coleoptera (Hansson 2002, Pikart et al. 2011), so Paracrias seems an unlikely candidate as a parasitoid of ants. The concepts of the genera Paracrias and Horismenus - which have morphological features in common (Hansson 2002) - were unclear at the time (1924) of the identification, so possibly this record actually also concerns a Horismenus species. Parasitism of ants is suspected but not verified for Myrmobomyia (Gumovsky and Bouček 2005), also an entedonine Eulophidae.

Systematic surveys of macro- and microfauna biodiversity directly within ant colonies are lacking (Hugues et al. 2008), especially in the Neotropics, and the hosts of most species of described eulophids are unknown. Parasitization of C. sp. ca. textor colonies by $H$. myrmecophagus is very low (less than $1 \%$ of ant pupae, Pérez-Lachaud and Lachaud, unpublished data). The very low prevalence of these myrmecophiles within ant nests, and the absence of targeted sampling methods to access their full biodiversity, may account for the rarity of records of eulophids associated with ants. The fact that in this single study two species of eulophids were recorded associated with ants stresses the likelihood that other eulophid species may also be associated with ants.

One hypothesized evolutionary path to parasitism of nest-building Hymenoptera, e.g. ants, by Hymenoptera parasitoids is via their non-hymenopterous symbionts, and then at some point in time a host shift has occurred (Hanson et al. in Hanson and Gauld 1995), as possibly exemplified by the two Horismenus species described here. We know nothing about the phylogenetic relationship between these two species but it 
would be interesting to know if $H$. myrmecophagus evolved after $H$. microdonophagus, thus possibly supporting this hypothesis.

\section{Acknowledgements}

We thank J.H.C. Delabie (Laboratório de Mirmecologia, CEPEC/CEPLAC, ItabunaBA, Brazil) for confirming the identification of the ant host. We also acknowledge the Department of Biology, Lund University for the use of their SEM facility.

\section{References}

Bouček Z (1972) Descriptions of new Eulophid parasites (Hym., Chalcidoidea) from Africa and the Canary Islands. Bulletin of Entomological Research 62: 199-205. doi: 10.1017/ S0007485300047647

Bonet A (2008) New hosts, host plants, and distribution records for Horismenus (Hymenoptera: Eulophidae) species in a bruchid beetle parasitoid guild attacking wild type Phaseolus coccineus and P. vulgaris in Central Mexico. Florida Entomologist 91: 698-701.

Gumovsky A, Bouček Z (2005) A new genus of Entedoninae from Malaysia, associated with ant nests (Hymenoptera, Eulophidae). Entomological Problems 35: 39-42.

Hanson PE, West-Eberhard MJ, Gauld ID (1995) Interspecific interactions of nesting Hymenoptera, pp. 76-88. In: Hanson PE, Gauld ID (Eds) The Hymenoptera of Costa Rica, Oxford University Press, Oxford, 893 pp.

Hansson C (2002) Eulophidae of Costa Rica, 1. Memoirs of the American Entomological Institute 67: 1-290.

Hansson C (2009a) Eulophidae of Costa Rica 3: Genus Horismenus. Memoirs of the American Entomological Institute 82: 1-916.

Hansson C (2009b) The genus Microdonophagus Schauff (Hymenoptera: Eulophidae), with description of a new species. Zootaxa 2200: 54-60.

Heraty JM (2002) A revision of the genera of Eucharitidae (Hymenoptera: Chalcidoidea) of the world. Memoirs of the American Entomological Institute 68: 1-367.

Hugues DP, Pierce NE, Boomsma JJ (2008) Social insect symbionts: evolution in homeostatic fortresses. Trends in Ecology and Evolution 23: 672-677. doi: 10.1016/j.tree.2008.07.011

Hölldobler B, Wilson EO (1990) The Ants. Springer-Verlag, Berlin-Heidelberg, 732 pp.

Kerrich GJ (1973) A revision of the tropical and subtropical species of the eulophid genus Pediobius Walker (Hymenoptera: Chalcidoidea). Bulletin of the British Museum (Natural History) (Entomology) 29: 115-199.

Kistner DH (1982) The social insects' bestiary, pp. 1-244. In: Hermann HR (Ed) Social Insects, vol. 3. Academic Press, New York, 459 pp.

Pérez G, Bonet A (1984) Himenópteros parasitoides de Acanthoscelides obtectus (Say) (Coleoptera: Bruchidae) en Tepoztlán, Morelos. Folia Entomológica Mexicana 59: 71-78. 
Philpott SM (2005) Changes in arboreal ant populations following pruning of coffee shadetrees in Chiapas, Mexico. Agroforestry Systems 64: 219-224. doi: 10.1007/s10457-0042372-2

Pikart TG, Souza GK, Costa VA, Hansson C, Zanuncio JC (2011) Paracrias pluteus (Hymenoptera: Eulophidae) in Brazil: new distribution and host records, and with a new host group for Paracrias. Zookeys 102: 77-82. doi: 10.3897/zookeys.102.1343

Rettenmeyer CW, Rettenmeyer ME, Joseph J, Berghoff SM (2011) The largest animal association centered on one species: the army ant Eciton burchellii and its more than 300 associates. Insectes Sociaux 58: 281-292. Supplemental material (doi: 10.1007/s00040-010 0128-8).

Schauff ME (1986) Microdonophagus, a new entedontine genus (Hymenoptera: Eulophidae) from Panama. Proceedings of the Entomological Society of Washington 88: 167-173.

Schauff ME, Bouček Z (1987) Alachua floridensis, a new genus and species of Entedoninae (Hymenoptera: Eulophidae) parasitic on the Florida carpenter ant, Camponotus abdominalis (Formicidae). Proceedings of the Entomological Society of Washington 89: 660-664.

Wheeler GC, Wheeler EH (1924) A new species of Schizaspidia (Eucharitidae), with notes on a eulophid ant parasite. Psyche 31: 49-56.

Wheeler GC, Wheeler JN (1986) The ants of Nevada. Natural History Museum of Los Angeles County, Los Angeles, 138 pp.

Wilson EO (1971) The Insect Societies. The Belknap Press of Harvard University Press, Cambridge, Mass., 548 pp. 